\title{
Chitosan Improves the Shelf Life of Domestic Chicken (Gallus gallus) Eggs against Staphylococcus aureus Contaminations
}

\author{
G. D. D. K. Gunasena, B. G. E. T. Jayashantha, and D. G. N. S. Senevirathne
}

\section{ABSTRACT}

In this study, in-vitro antibacterial activity of four different concentrations $(0.00 \%, 0.05 \%, 0.10 \%$, and $0.15 \%$ w/v\%) of chitosan, a natural biopolymer, was tested against the foodborne pathogen Staphylococcus aureus ATCC 25923 using well diffusion and colony counting methods. The organism showed the highest sensitivity to $1.50 \%$ chitosan, while the antibacterial effect was raised with increasing concentration of chitosan in the medium. Microbiological testing of randomly selected village chicken egg samples obtained from a market in Kiribathgoda, Sri Lanka revealed high cell counts of $S$. aureus greater than $5 \log \mathrm{CFU} / \mathrm{mL}$, which exceeded the maximum accepted limit $(3 \log \mathrm{CFU} / \mathrm{g})$ that should be present in poultry based raw products according to SLS 1161:2003 guidelines, indicating a potential risk for presence of preformed Staphylococcal enterotoxins in these eggs. Therefore, a sample containing randomly selected, 90, six-pooled eggs from the same source was used to investigate the in-vivo antibacterial efficacy of $1.50 \%$ chitosan (coated on the surface of eggshells) against this pathogen. Both chitosan coated eggs and chitosan non-coated eggs (except raw eggs) were externally inoculated from $\sim 5 \mathrm{log}$ $\mathrm{CFU} / \mathrm{mL}$ of the bacterial inoculum and monitored for 28 days, where it showed a bacteriostatic activity with $4 \log$ CFU/ mL and $3 \log$ CFU/ mL fold growth reductions compared to chitosan non-coated eggs and raw eggs respectively. These experimental results suggest that chitosan coating is a promising method to protect the microbial quality and safety of domestic chicken eggs regarding $S$. aureus contaminations.
Published Online: February 2, 2021

ISSN: 2684-5199

DOI:10.24018/ejbio.2021.2.1.139

G. D. D. K. Gunasena

Department of Microbiology,

University of Kelaniya, Sri Lanka.

(e-mail: deepthi@kln.ac.lk)

B. G. E. T. Jayashantha

ORANA Sri Lanka Liaison Office, Boralesgamuwa, Sri Lanka.

(e-mail: eranga.thilina ${ }^{\circledR}$ oranagroup.dk) D. G. N. S. Senevirathne * Department of Microbiology,

University of Kelaniya, Sri Lanka. (e-mail: nash94.nick@gmail.com)

*Corresponding Author

Keywords: Antibacterial activity, Chitosan, Chicken eggs, Staphylococcus aureus.

\section{INTRODUCTION}

Staphylococcus aureus is one of the most common pathogenic bacteria that contaminates poultry products. According to reference [1], Staphylococcus aureus is responsible for $75 \%$ of total egg infecting-bacteria. In most cases, S. aureus was isolated from eggshells. According to some authors, this pathogen can resist against the natural antimicrobial compounds present inside eggs, and grow on their shells as well as in the internal content [1], [2]. Aged eggs are more prone for Staphylococcal infection than fresh eggs. This may be due to the absence of outermost cuticle layer on aged eggs [3]. During consumption of these contaminated eggs, ingestion of enterotoxins preformed in eggs by coagulase-positive $S$. aureus strains can lead to Staphylococcal food poisoning, which is among the most prevalent foodborne diseases worldwide [4].

Contamination of eggs can take place in various ways. The main way of contamination is direct contact with the pathogen. S. aureus is a universal organism largely present on skins and wounds of hens, on the floor of farms, and hands of egg collectors [2], [5]. Therefore, lack of proper sanitation practices is the major cause for the direct contamination of $S$. aureus with chicken eggs Staphylococcal infections to egg-laying hens may cause major economic impacts as they can be responsible for reduction of egg yield as well as death of these animals [2]. Vaccination of hens and application of antibiotics against Staphylococcus aureus are conventional methods to get rid of $S$. aureus contamination in poultry. But health concerns and side effects of these methods, for instance, possibility for presence of remaining active viral particles and development of antibiotic-resistant strains, have urged the researchers to look for alternative methods [6], [7].

Chitosan is chemically known as $(1 \rightarrow 4)$-linked 2-amino 2 -deoxy- $\beta$-D-glucan, which is a linear, polycationic, and high molecular weight hetero-polysaccharide synthesized from deacetylation of chitin in crustacean shells [8], [9]. Recently, chitosan has received more attention for commercial use in biomedical and food industries owing to its distinctive properties. Its antimicrobial activity against a large number of foodborne pathogens, and the ability to form edible films or coatings make it a potential source of food preservation in food industry [10]-[12]. To further advantage, chitosan has been proved as a biocompatible and non-toxic compound for biological applications. Many 
hypotheses attempt to explain the mode of antimicrobial action of chitin, a change in cell permeability due to ionic interactions between chitosan and microbial cell membranes being the most feasible one, yet no definite elucidation has been done [11], [13].

Recent studies have revealed the effectiveness of applications of chitosan in protecting the internal quality of eggs, thus extending their shelf life by modifying the atmosphere inside and lowering the transpiration losses [14]-[17]. Its antibacterial activity against prominent foodborne pathogens such as different serovars of Salmonella enterica and Listeria monocytogenes [18] in eggs and meat products [19], [7] has also been studied extensively. However, information on use of chitosan as a natural protective agent in preserving domestic chicken eggs against Staphylococcal infections is meager in the scientific literature. Therefore, the objective of the present study was to assess the antibacterial effect of chitosan coating on Gallus gallus eggshells under both in-vitro and in-vivo conditions to reduce $S$. aureus contaminations, in order to enhance the consumer safety of the eggs.

\section{MATERIALS AND METHODS}

\section{A. Preparation of the Staphylococcus aureus Mid- Exponential Phase Culture}

The Bacterial culture was prepared using the method described by reference [20]. Staphylococcus aureus ATCC 25923 was obtained from the bacterial culture collection of Department of Microbiology, University of Kelaniya, Sri Lanka. The stock cultures were maintained by regular subculturing on nutrient agar (Himedia; M001) slants at $4{ }^{\circ} \mathrm{C}$ and transferred monthly. A loopful of the bacterium was inoculated into $10 \mathrm{~mL}$ of tryptone soy broth (TSB) (Oxoid; CM0129B) and incubated at $37{ }^{\circ} \mathrm{C}$ overnight. An aliquot $(0.1 \mathrm{~mL})$ from the overnight (18 hours) culture was again transferred to TSB and incubated at $37{ }^{\circ} \mathrm{C}$ overnight. This procedure was used to obtain the bacterial culture in mid-exponential phase.

\section{B. In-Vitro Assay}

\section{Preparation of Chitosan Broths with Different Concentrations}

Different concentrations of chitosan solutions were prepared using the method described by reference [20]. Chitosan solutions of $0.00 \%, 0.50 \%, 1.00 \%, 1.50 \%$ (w/v \%) were prepared by using shrimp shell chitosan (Himedia; RM9358, degree of deacetylation $\geq 75.00 \%$ ). Acetic acid $(2 \% \mathrm{v} / \mathrm{v} \%)$ was used as the solvent to dissolve chitosan in each dilution. $\mathrm{pH}$ of each dilution was adjusted to 5.5 using $\mathrm{NaOH}$. $(10 \mathrm{~mL})$ from each chitosan dilution was inserted in to $100 \mathrm{~mL}$ sterile Erlenmeyer flask containing $20 \mathrm{~mL}$ of nutrient broth (Himedia; M002).

\section{Inoculation of Organisms}

The broths were inoculated with $0.10 \mathrm{~mL}$ of the prepared culture of Staphylococcus aureus. The broths were incubated in a shaker at room temperature.

\section{Colony Counting Method}

$1 \mathrm{~mL}$ sample from each flask was taken at different time intervals $(0,2,6,8$ days) and diluted appropriately using peptone water (Lab M; MC024). This was followed by duplicate surface-plating of $0.1 \mathrm{~mL}$ of dilutions on selective agar medium. Samples containing Staphylococcus aureus were plated on Baird Parker agar (Oxoid; CM0275) with egg yolk tellurite emulsion (Himedia; FD046) using surface spread technique and incubated at $37 \pm 1{ }^{\circ} \mathrm{C}$ for 24 to 48 hours. After the incubation period, typical colonies in plates were counted and cell counts were calculated in each prepared solution. Typical S. aureus colonies on Baird Parker agar with egg yolk tellurite emulsion medium were identified as dark grey or black colour circular (diameter; $1.5 \mathrm{~mm}-3.0 \mathrm{~mm}$ ) colonies with clear zones.

\section{Well Diffusion Method}

Tryptone soy agar (Oxoid; CM0131) was prepared and aseptically poured into sterile petri plates with similar dimensions. The plates were allowed to solidify in the Laminar flow cabinet for about 1 hour. Four wells (diameter $=5 \mathrm{~mm}$ ) were aseptically created in each TSA plate using a sterile cork borer. $0.1 \mathrm{~mL}$ from the Staphylococcus aureus culture was inoculated and spread over the surface of the plates. The plates were allowed to dry in the laminar flow cabinet until the bacterial lawn is adsorbed on the agar surface. $0.1 \mathrm{~mL}$ from a prepared chitosan solution was inserted into the four wells of a plate. Likewise, different chitosan solutions were filled into different plates. One TSA plate with four wells was used for a distinct chitosan concentration. The plates were refrigerated at $4{ }^{\circ} \mathrm{C}$ for 3 hours to allow diffusion of chitosan through the medium. The plates were incubated in lids-uppermost position at $37{ }^{\circ} \mathrm{C}$ for 24 to 48 hours. Zones of inhibition were measured to the nearest $1 \mathrm{~mm}$ after the incubation period.

\section{In-Vivo Assay}

\section{Detection and Isolation of Staphylococcus aureus from Eggs}

Eggs sample (containing 3 "domestic chicken eggs" purchased from Kiribathgoda market) were blended for 1 minute in a sterile blender and the contents were aseptically transferred into a sterile beaker. $1 \mathrm{~mL}$ from egg contents was transferred in to a $9 \mathrm{~mL}$ of sterile peptone water (Lab $\mathrm{M}$; MC024) to make the initial suspension. Decimal dilutions were prepared using the peptone water. For the detection of Staphylococcus aureus in eggs, Standard method included in ISO 6888-1:1999 (Microbiology of food and animal feeding stuffs - Horizontal method for the enumeration of Coagulase positive Staphylococci using Baird-Parker agar medium) [21] was followed. $0.1 \mathrm{~mL}$ from each prepared peptone water tube was aseptically transferred to Baird Parker agar (Oxoid; CM0275) with egg yolk Tellurite emulsion (Himedia; FD046) plates and inoculated using surface inoculation technique. Plates were allowed to dry for 15 minutes inside the Laminar flow cabinet. The plates were incubated at $37 \pm 1{ }^{\circ} \mathrm{C}$ for 24 to 48 hours. After the incubation period, Dark grey/ black colonies with clear zones were counted in each plate. Few selected colonies were subjected into Gram staining and slide coagulase test using the modified human plasma obtained from the Faculty of Medicine, University of Kelaniya, Sri Lanka. Presence of Staphylococcus aureus was confirmed by clump formation 
while adding and mixing the modified human plasma in slide coagulase test.

\section{Preparation of Staphylococcus aureus Mid-Exponential Phase Cultures}

A mid-exponential phase culture of $S$. aureus was prepared using the method described by [22]. A freshly inoculated stock culture of Staphylococcus aureus ATCC 25923 was obtained from the bacterial culture collection in Department of Microbiology, University of Kelaniya, Sri Lanka. The stock culture was maintained by regular subculturing on Nutrient agar (Himedia; M001) slants at $4 \pm 1{ }^{\circ} \mathrm{C}$. A loop full was inoculated to $10 \mathrm{~mL}$ of Tryptone Soy Broth (Oxoid; CM0129B) and incubated at $37 \pm 1{ }^{\circ} \mathrm{C}$ overnight. An aliquot $(0.1 \mathrm{~mL})$ from the overnight $(18$ hours) culture was again sub-cultured into TSB and was grown at $37 \pm 1{ }^{\circ} \mathrm{C}$ overnight. This procedure was used to make $S$. aureus culture in mid-exponential phase.

\section{Enumeration of Bacteria in TSB Broth}

A dilution series containing $10^{-1}$ to $10^{-10}$ of the midexponential phase $S$. aureus culture was prepared by using sterile buffered peptone water. $0.1 \mathrm{~mL}$ from each dilution was inoculated on Baird Parker agar with egg yolk Tellurite emulsion using surface inoculation technique. The plates were incubated at $37 \pm 1{ }^{\circ} \mathrm{C}$ for 24 to 48 hours. After the incubation period, typical colonies were counted in each plate. S. aureus viable cell count in the mid-exponential phase culture were also calculated. Amount of viable Staphylococcus aureus cells in the mid-exponential phase was $2.4 \mathrm{E}+09 \mathrm{CFU} / \mathrm{mL}$ and therefore, in order to make Staphylococcus aureus solution $(1000 \mathrm{~mL})$ of $10^{5}$ initial number of viable cells per $\mathrm{mL}$, following steps were performed.

Tryptone soy broth $1000 \mathrm{~mL}$ was poured aseptically in to $2000 \mathrm{~mL}$ plastic beaker. $0.1 \mathrm{~mL}$ portion from midexponential phase $S$. aureus culture was aseptically transferred into the beaker and mixed well using a sterile glass rod. This solution should technically contain $\sim 10^{5}$ $\mathrm{CFU} / \mathrm{mL}$ cells of $S$. aureus as the initial inoculum to apply on eggs. This solution was used for further steps immediately.

\section{Preparation of $1.5 \%(w / v)$ chitosan in $2 \%(v / v)$ Acetic Acid and $2 \%$ Glycerol Solution}

$7.5 \mathrm{~g}$ of shrimp shell derived Chitosan (Himedia; RM9358, degree of deacetylation $\geq 75.00 \%$ ) was aseptically added in to a sterile $1000 \mathrm{~mL}$ beaker. Sterile $2 \%$ acetic acid $(1000 \mathrm{~mL})$ was added into the same beaker and mixed well using a sterile glass rod. This chitosan solution was shaken overnight at $40 \pm 1{ }^{\circ} \mathrm{C} .10 \mathrm{~mL}$ of Glycerol was added to the same solution as a plasticizer and stirred for 30 minutes. Finally, pH was adjusted to 5.5 .

\section{Collection and Pre-Treatment of Chicken Eggs}

Domestic chicken eggs (97) were randomly collected from Kiribathgoda market ("Pola") and among them, 90 non-cracked eggs were subjected to the experiment. They were grouped in to three groups. Each group consisted with 24 eggs. All eggs of the three groups were washed with $70 \%$ Ethanol solution by dipping in $500 \mathrm{~mL}$ of $70 \%$ Ethanol in
$1000 \mathrm{~mL}$ beaker. All the eggs were allowed to dry in the laminar flow cabinet for 2 minutes. Eggs of each group were stored on separate "eggs storing plastic trays". (These trays were chemically disinfected by applying $70 \%$ Ethanol). The "group 1" eggs were incubated at $37 \pm 1{ }^{\circ} \mathrm{C}$ until they were subjected to further testing procedures. Eggs of "group 3" were washed with freshly prepared $1.5 \%(\mathrm{w} / \mathrm{v})$ Chitosan in $2 \%(\mathrm{v} / \mathrm{v})$ Acetic acid and 2\% Glycerol solution by aseptically immersing in $500 \mathrm{~mL}$ of prepared Chitosan solution in $1000 \mathrm{~mL}$ sterile beaker. The eggs were kept on a sterile plastic tray and allowed to dry under the laminar flow for 15 minutes. As the next step, both "group 2" and "group 3" eggs were treated by freshly prepared mid-exponential phase Staphylococcus aureus culture which consists of $\sim 10^{5}$ CFU/ mL cells. At this step, the eggs were aseptically submerged in the bacterial solution and allowed to dry under a fan on a sterile plastic tray for 15 minutes. The two plastic trays containing "group 2" and "group 3" eggs were incubated at $37 \pm 1{ }^{\circ} \mathrm{C}$ until they were subjected to further testing procedures. After that two plastic trays containing "group 2" and "group 3" eggs were incubated at $37 \pm 1{ }^{\circ} \mathrm{C}$ until they were subjected to further testing procedures.

Each group of eggs can be denoted as below,

Group 1 - Raw eggs (But the outside of the shell was sterilized by $70 \%$ Ethanol)

Group 2 - Chitosan noncoated but contaminated with Staphylococcus aureus

Group 3 - Chitosan-coated and contaminated with Staphylococcus aureus

Six-pooled eggs from each group per week were taken for the enumeration of Staphylococcus aureus in egg contents.

\section{Enumeration of Staphylococcus aureus in Three Groups of Eggs}

For the enumeration of Staphylococcus aureus in eggs, ISO 6888-1:1999 (Microbiology of food and animal feeding stuffs - Horizontal method for the enumeration of Staphylococcus aureus using Baird-Parker agar medium) was used. Six-pooled eggs from each group at a time were blended for 1 minute in a sterile blender and the contents were transferred in to separate sterile beakers. $1 \mathrm{~mL}$ of Egg contents from each beaker was transferred in to a $9 \mathrm{~mL}$ of sterile peptone water ( $\mathrm{Lab} 67 \mathrm{M}, \mathrm{MC} 024)$ to make the initial suspension and decimal dilutions (from $10^{-1}$ to $10^{-8}$ ) were prepared using the peptone water for each group of egg contents. $0.1 \mathrm{~mL}$ aliquot from each peptone water was aseptically transferred to Baird Parker agar (Oxoid; CM0275) with egg yolk Tellurite emulsion (Himedia; FD046) plates and inoculated using surface spread technique. Plates were allowed to dry for 15 minutes inside the Laminar flow cabinet and they were incubated at $37 \pm 1{ }^{\circ} \mathrm{C}$ for 24 to 48 hours. After the incubation period, Dark gray to black circular shaped $1.5 \mathrm{~mm} \mathrm{-} 3.0 \mathrm{~mm}$ colonies with clear zones were counted in each plate using the standard equation below. Few selected colonies were subjected to the slide coagulase test using coagulase plasma obtained from the Faculty of Medicine, University of Kelaniya, Sri Lanka. This procedure was performed for all 3 groups of eggs for next 4 weeks ( $\sim$ month) of time. 


\section{RESUlTS AND DisCUSSION}

This study was planned to evaluate in-vitro and in-vivo antimicrobial effects of chitosan-coated chicken eggs against Staphylococcus aureus contaminations. The entire experiment was performed as four subexperimental stages. The first part of the experiment was performed to determine the chitosan concentration which shows the highest antimicrobial activity against the Staphylococcus aureus using two methods: colony counting method and well diffusion method. The aim of this step was to select a suitable chitosan concentration for the next steps of the study.

TABLE 1: VIABLE STAPHYLOCOCCUS AUREUS CELLS (CFU/ ML) IN DiFFERENT CHITOSAN SOLUTIONS IN THE COLONY COUNT METHOD

\begin{tabular}{ccccc}
\hline \multirow{2}{*}{ Day } & \multicolumn{4}{c}{ Chitosan Concentration } \\
\cline { 2 - 5 } & $0 \%$ & $0.5 \%$ & $1 \%$ & $1.5 \%$ \\
\hline 1 & $5.5 \mathrm{E}+04$ & $5.5 \mathrm{E}+04$ & $5.5 \mathrm{E}+04$ & $5.5 \mathrm{E}+04$ \\
3 & $5.5 \mathrm{E}+04$ & $5.5 \mathrm{E}+04$ & $7.2 \mathrm{E}+03$ & $5.5 \mathrm{E}+03$ \\
7 & $5.4 \mathrm{E}+04$ & $5.2 \mathrm{E}+04$ & $5.5 \mathrm{E}+03$ & $5.5 \mathrm{E}+03$ \\
9 & $3.3 \mathrm{E}+04$ & $1.5 \mathrm{E}+04$ & $5.5 \mathrm{E}+03$ & $5.5 \mathrm{E}+03$ \\
\hline
\end{tabular}

TABLE 2: MEAN VALUES OF THE DIAMETERS OF CLEAR ZONES (MM) GIVEN BY STAPHYLOCOCCUS AUREUS IN DIFFERENT CHITOSAN SOLUTIONS IN THE WELL DIFFUSION METHOD

\begin{tabular}{ccccc}
\multicolumn{5}{c}{ IN THE WELL DIFFUSION METHOD } \\
\hline \multirow{5}{*}{ Average diameter of clear zones $(\mathrm{mm})$} \\
\cline { 2 - 5 } & $0.0 \%$ & $0.5 \%$ & $1.0 \%$ & $1.5 \%$ \\
\hline 1 & 0 & 10 & 10 & 11 \\
3 & 2 & 5 & 5 & 7 \\
7 & 0 & 9 & 10 & 10 \\
9 & 0 & 7 & 9 & 10 \\
Mean & 1 & 8 & 9 & 10 \\
\hline
\end{tabular}

In the second part, five samples of 3-pooled "domestic chicken eggs" from Kiribathgoda market were tested in order to isolate Staphylococcus aureus. Microbiological testing in this step was performed by following ISO 68881:1999 (Microbiology of food and animal feeding stuffs Horizontal method for the enumeration of coagulasepositive Staphylococcus aureus using Baird-Parker agar medium) standard procedures [21]. The objective of this part was to find out the prevalence of $S$. aureus in domestic chicken eggs collected in the Kiribathgoda market.

The final part was the key experiment in this study. Thereby, mid-exponential phase Staphylococcus aureus culture was inoculated on chitosan-coated chicken eggs and the antibacterial action of chitosan was compared with that of chitosan-noncoated and raw chicken eggs.

The third part of the experiment was carried out to enumerate a number of viable Staphylococcus aureus cells in the mid-exponential phase. The goal of this step was to prepare a mid-exponential phase Staphylococcus aureus solution $(1000 \mathrm{~mL})$ with $5 \log \mathrm{CFU} / \mathrm{mL}$ initial number of viable cells $\left(10^{5} \mathrm{CFU} / \mathrm{mL}\right)$ in order to apply to the eggs in the final step. Staphylococcus aureus solution with $10^{5}$ CFU/ mL initial number of cells was used to apply for chicken eggs because, that concentration of cells is considered as the minimum number of cells which is required by $S$. aureus to express its agr system via quorum sensing in order to produce Staphylococcal enterotoxins which are responsible for the food poisoning [7], [23].

Mid-exponential phase bacterial cultures of $S$. aureus were used in the first and final parts of the study because, that phase in the growth curve provides the maximum growth rate and maximum cellular activities. It is the phase at which most of the bacteria show the highest sensitivity for most of the antimicrobial compounds. But in the case of chitosan, different researchers have observed different results for different types of organisms. According to reference [24], Chitosan-treated Staphylococcus simulans was inhibited at the stationary phase. According to reference [25], E. coli cells have shown growth reduction at the late exponential phase. This suggests that the growth phase at which chitosan affects is different in different types of organisms. Not only intrinsic factors, but also extrinsic factors such as media composition and other growth factors may also affect for this fact. Tryptone soy broth was used to make the mid-exponential phase bacterial cultures because it supports a luxuriant growth of many fastidious organisms.

All the chicken eggs used for this experiment were Domestic chicken eggs. They were taken from the same place in the Kiribathgoda market ("Kiribathgoda pola"). Domestic chicken eggs were used for the entire experiment rather than using "farm eggs" due to few reasons. In properly managed poultry farms, hens are vaccinated against Staphylococcal infections [6]. Antibodies which are generated by the vaccination can be transmitted to the egg as transplacental manner during the formation of egg. Therefore, such kind of eggs may contain particular antibodies against particular pathogens. Hence, these testing organisms may rarely grow inside the egg, if they could penetrate through the pores of eggshell. In this case, false positive results may be observed, because inhibition of the pathogen is likely to be performed by chitosan. But actually, the inhibition has been occurred due to the activity of antibodies (immunoglobulins) in the egg. On the other hand, domestic hens are not generally vaccinated. Therefore, inhibition of the pathogen in chitosan-coated domestic eggs clearly reflect the antibacterial activity of chitosan.

Also, commercial level farm eggs are treated for preservation. There are several ways for preservation of raw eggs. They are cleaned after laying and sometimes, mineral oil is applied in order to extend the shelf life. These treatments change physiological and biological conditions of eggs. These treatments can affect for the natural growth of the testing organisms. But domestic eggs are not subjected to such kind of treatments. They are fresh and natural in condition. Domestic eggs are normally contaminated by fecal matter. Generally, they are not cleaned before selling. Fecal contamination provides inherent microflora and sometimes there can be pathogenic organisms as well. Therefore, domestic eggs are more contaminated than commercial farm eggs. In order to prevent aforementioned complications and false positive results, this study was carried out by using domestic chicken eggs rather than using commercial farm eggs. By interviewing the seller, it was confirmed that the eggs were taken from domestic-level poultry cages and they were not subjected to any treatments. However, the final outcome of this study can be applied for domestic chicken eggs as well as commercial level farm eggs.

Eggs which were taken from the Kiribathgoda market were pooled randomly before subjecting to the testing procedures in experiments in the second and fourth parts of this study. In the second part, one randomly pooled egg 
sample was composed with 3 eggs, while in the final part it was composed with 6 eggs. Reason for pooling eggs was to reduce the effects caused by different matrices. Even though the eggs are taken from the same place, there can be changes in physiochemical differences (nutrient content, size of micropores on the shell, thickness and hardness of the shell and etc.) in eggs because, they might be taken from different types and breeds of hens. Type, breed, age and health condition of egg laying hen, sanitation in the egg laying cages and sanitation of egg collectors are some factors which determine the initial microbial flora on the eggshell as well as in the internal contents of eggs. By pooling eggs, these effects due to different matrices could be theoretically eliminated.

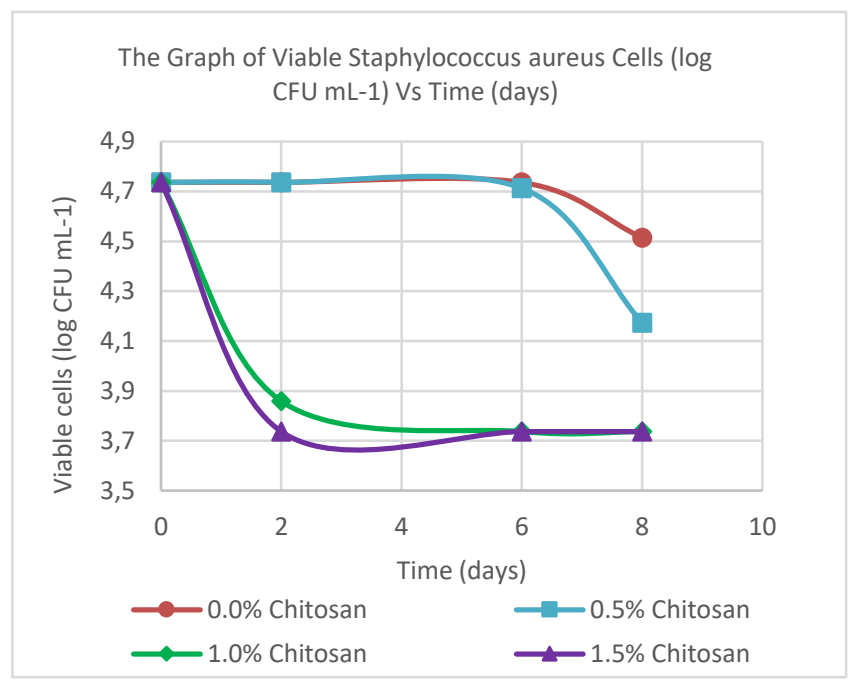

Fig. 1. Graphical representation of the antibacterial activity of different concentrations of chitosan with time against Staphylococcus aureus.

Results obtained from the first part were used to plot the Fig. 1, which shows the antibacterial activity of different chitosan concentrations with time for $S$. aureus. According to the graph, only $1.00 \%$ and $1.50 \%$ chitosan solutions have shown a growth reduction for Staphylococcus aureus. The highest growth reduction was shown by $1.5 \%$ chitosan solution. It has shown $1 \log$ reduction within 2 days under invitro conditions. These two chitosan solutions have demonstrated bacteriostatic action by maintaining the bacterial growth in the same level. $0.50 \%$ Chitosan solution and the control $(0.00 \%$ chitosan $)$ didn't show any growth reduction. After 6 days, S. aureus growth in control and $0.50 \%$ chitosan solution began to decrease, because of the population might have reached to its death phase. Since the bacterial population was grown in batch cultures, nutrients in the medium might be deficient after 6 days. But the death phase was slightly accelerated in $0.50 \%$ chitosan solution than in control.

Results for this part in the present study were deviated from the results obtained reference [20]. He observed a complete growth inhibition $\left(<10^{2} \mathrm{CFU} / \mathrm{mL}\right)$ for $S$. aureus within 1 day, for the same chitosan concentrations $\mathrm{pH}$ (5.5). This might be occurred due to differences between the properties of chitosan and S. aureus strains used in the two studies. The present study used shrimp-derived chitosan with degree of deacetylation $\geq 75.00 \%$. But, physiochemical properties of chitosan used in the past study was not mentioned by Wang [20]. There are Staphylococcus aureus strains with highly positive cell surface charges. Such strains show reduced susceptibility for antibacterial effect of chitosan, while the strains with highly negative cell surface charges show high sensitivity for the antibacterial effect [24].

Fig. 2 shows the relationship between the diameter of clear zones (in millimeters) and concentration of chitosan solution $(\mathrm{w} / \mathrm{v} \%)$. It is related to the well diffusion method of determining the chitosan concentration, which shows the highest antibacterial activity against $S$. aureus. The graph was plotted using the results from the table 2. The graph shows linear increments for $S$. aureus, which suggest the increase of antimicrobial activity with increasing chitosan concentrations.

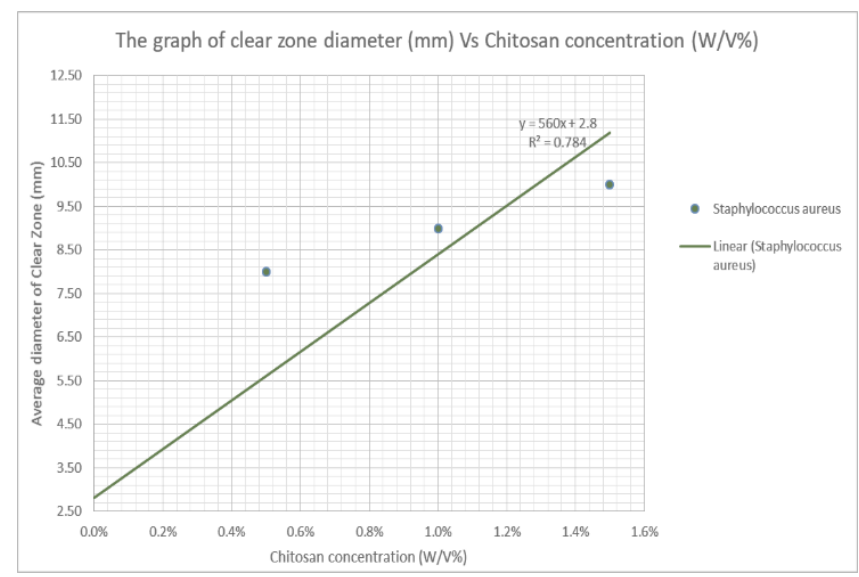

Fig. 2 Relationship between the diameter of clear zones (in millimeters) for S. aureus and concentration of chitosan solution (w/v \%).

The highest antibacterial activity for the organism was shown at $1.50 \%$ chitosan solution. It was the highest tested chitosan concentration used in this study. Sometimes, more concentrated chitosan solutions (than 1.50\%) may give greater antimicrobial activity. During a previous study [20], scientists tested antimicrobial activity of chitosan in five species of microorganisms including Staphylococcus aureus up to $2.50 \%$ chitosan concentration. Thereby, the highest antibacterial activity for $S$. aureus was exhibited by $2.50 \%$ chitosan solution. But this study was performed up to $1.50 \%$ chitosan because, increasing the concentration caused to rise the viscosity of the solution rapidly. It made harder to dissolve chitosan in $2.0 \%$ acetic acid. This problem was arisen for chitosan solutions which was higher than $1.50 \%$. This may cause practical problems while they are applying to the eggs.

Viscosity of the chitosan solution depends on the degree of deacetylation, molecular weight, temperature and concentration [24], [26], [27]. Molecular weight is the major effector for the viscosity in chitosan solutions when temperature and $\mathrm{pH}$ are kept as constants. Molecular weights of chitosan used were not available in present study as well as in reference [20]. That is why $1.50 \%$ chitosan solution was selected after series of trial-and-error experiments regarding the solubility and the viscosity of the solution. $1.50 \%$ chitosan was found as the best, highest chitosan solution to apply for eggs without viscosity problems during the preparation. On the other hand, it showed the highest antibacterial activity against $S$. aureus among other 
chitosan concentrations used. Therefore, according to the results of the first part of the experiment, $1.50 \%$ chitosan solution was selected as the best chitosan solution for coating chicken eggs in the in-vivo assay.

Staphylococcus aureus was detected in every tested egg sample. All the egg samples were contaminated with high amounts of $S$. aureus. All the tested samples exceeded the safe limit for consumption as food. Staphylococcus aureus has ability to produce its poisonous exotoxins in populations higher than 5 to $6 \log \mathrm{CFU} / \mathrm{mL}$. However, it does not produce exotoxins unless the population is infected by the specific phages, which mediates the toxin production. Nevertheless, there is a high potential risk of production of toxins. Therefore, cell counts higher than 3-4 log CFU/ mL is not suitable for human consumption as food. In Sri Lanka, $3 \log \mathrm{CFU} / \mathrm{mL}$ of $S$. aureus cell count is generally considered as the maximum limit of a poultry or meat associated food material which is accepted to consume as stated in SLS 1161:2003 standard [28]. Accordingly, it is clear that no egg samples are suitable to use as food. The eggs used in the experiment-part 2 were randomly selected from the bulk of eggs, which were stored in room temperature to sell for customers. All the eggs were "domestic chicken eggs". More information about these eggs were collected by interviewing the sellers. According to their explanations, not all the egg were newly laid ones. Normally, they keep one egg for about 14 days of period for purpose of selling. They are used to store newly laid eggs with old eggs in the same place. This can cause cross contaminations. Bacterial flora including S. aureus on the shells of old eggs can easily contaminate newly stored eggs. We noticed that the sellers did not concern about sanitary practices while handling the eggs for selling. These activities can easily migrate $S$. aureus on hands and on the skin of sellers to the eggshells. Trays, boxes or cupboards that used to keep eggs for selling were not cleaned properly after repeated using. All of these inappropriate practices of sellers might cause for higher degree of contamination of tested chicken eggs samples in this study. Any kind of chicken egg including commercial farm eggs can be contaminated under these conditions and selling practices.

TABLE 3: Results OF COLONY COUNTS OF S. AUREUS IN THE TESTED EGGS SAMPLES OBTAINED FROM THE MARKET

\begin{tabular}{ccccc}
\multicolumn{5}{c}{ EGGS SAMPLES OBTAINED FROM THE MARKET } \\
\cline { 3 - 5 } Day & $\begin{array}{c}\text { Egg } \\
\text { Sample }\end{array}$ & Eggshell & $\begin{array}{c}\text { Internal } \\
\text { content }\end{array}$ & Whole egg \\
\hline 1 & 1 & $\mathrm{NA}$ & $\mathrm{NA}$ & $2.1 \mathrm{E}+07$ \\
13 & 2 & $\mathrm{NA}$ & $\mathrm{NA}$ & $>5.5 \mathrm{E}+07$ \\
22 & 3 & $>3.0 \mathrm{E}+05$ & $>3.5 \mathrm{E}+05$ & $\mathrm{NA}$ \\
36 & 4 & $1.6 \mathrm{E}+05$ & $3.3 \mathrm{E}+05$ & $\mathrm{NA}$ \\
41 & 5 & $1.4 \mathrm{E}+05$ & $3.5 \mathrm{E}+05$ & $\mathrm{NA}$ \\
\hline
\end{tabular}

According to the results in the Table 3, higher number of $S$. aureus cells were found from the internal contents than on shells. But the deference of cell counts between the eggshell and internal contents were less than $1 \log \mathrm{CFU} / \mathrm{mL}$. Even though $S$. aureus cell counts on the shell and the interior of egg were not significantly different (Paired-T test using Minitab 17.0; $\mathrm{T}-$ Value $=2.98$, table value $=4.31$ at 0.05 confidence level), there was an observable difference between the cell counts. The most possible way of contamination of eggs by $S$. aureus is the external contamination after the egg is laid. There is a little possibility of trans-ovarian contamination during the production of egg inside the hen. That can happen only when the hen is infected by $S$. aureus. Therefore, the most possible way of contamination is horizontal contamination. Soon after the egg is laid S. aureus on the skin and feathers of hen can migrate to the eggshell. It might be the initial contamination.

Later, further contamination can be occurred during handling, transportation and storing of eggs by the poultry farmer and the seller. In all the above steps, eggshell is contaminated first. Egg shell acts as a natural barrier for microorganisms. Even the eggshell is porous, cuticle layer which is the outermost part of newly laid eggs prevents entry of microorganisms into the egg. But this layer is naturally degraded soon with the time. $S$. aureus cells which are initially colonized on the eggshells might be grown on the eggshell by consuming nutrients on the egg shell.

Generally, there is less amount of nutrients on the shell than in the interior of eggs. Bacterial population consume nutrients on the shell. With time, nutrients on individual eggshells will be reduced. When there is a lack of adequate nutrients to grow, the bacterial population may reach to a stationary phase. In this stage bacteria on the shell may live with a nutrient-deficient stage. Some $S$. aureus cells may live as starved during this period. With the degradation of cuticle, initially colonized bacteria may get a passage to enter into the egg via micro-pores on the eggshell. Nonmotile bacteria such as $S$. aureus can migrate into the egg by the diffusion and Brownian motion through the pores of shell. After getting into the egg, these bacterial cells are grown rapidly with higher growth rates because there is a large amount of nutrient content inside the egg. Some of the starved cells are activated and starts cell division rapidly in this highly nutritious medium (internal contents of eggs). This rapid growth of bacteria inside the egg can exceed the cell counts on the shell with time. It is the usual method of colonization of $S$ aureus inside the egg and this phenomenon can be used to describe how the $S$. aureus cell counts in internal contents was greater than on surface of eggshells in this experiment.

Staphylococcus aureus was used for the next steps of this study because, it is found as the major pathogenic bacterium which contaminates commercial chicken eggs [1]. Final experiment is the main part of and the most important section of this entire study. Other previous experiments were carried out to get important information to perform the final experiment in a successful manner. In this part, chitosan was directly applied to the eggs and its antibacterial activity against Staphylococcus aureus was investigated.

For enumeration and monitoring the bactericidal or bacteriostatic activity of chitosan, viable cell count of initial inoculum should be known. The third part was carried out for this purpose. A mid exponential phase $S$. aureus was obtained by following the method used by Fernandez-Saiz and colleagues [20]. The same procedure was used by some of the other researchers. The mid-exponential phase culture was used because that phase in the growth curve provides the maximum growth rate and maximum cellular activities. It is the phase which most of the bacteria show highest sensitivity for most of the antimicrobial compounds. A freshly inoculated stock culture was used because fresh 
cultures were not affected by any unfavorable biochemical and physiological conditions.

According to the results of the part 3, the preferred procedure of making mid- exponential phase bacterial culture had given $2.4 \mathrm{E}+09 \mathrm{CFU} / \mathrm{mL}$ number of $S$. aureus viable cells. This information was helpful for the preparation of a fresh $S$. aureus mid-exponential phase culture containing approximately $10^{5}$ initial number of viable cells per milliliter.

Next, S. aureus $\sim 10^{5} \mathrm{CFU} / \mathrm{mL}$ mid-exponential phase culture was used to apply for eggs because it is the threshold concentration of $S$. aureus cells to produce staphylococcal enterotoxins. Eggs that contain $S$. aureus counts higher than $10^{3} \mathrm{CFU} / \mathrm{mL}$ are considered as non-accepted for commercial use. Therefore, commercially available eggs should contain low $S$. aureus counts than the size of inoculum, which was infected to the eggs in this study.

All eggs were washed with $70 \%$ ethanol prior to applying chitosan because, removal of $S$. aureus cells which were already present on the shells of eggs, should be needed. After this step, there would not be any $S$. aureus viable cells on shell surfaces of eggs. Therefore, eggs were handled using sterile gloves and different sterile gloves were used to handle each group of eggs, Aseptic techniques were used strictly with paying more attention in order to prevent recontamination of $S$. aureus prior to the next steps.

TABlE 4: Viable Staphylococcus aureus Cells in PoOled EgG

\begin{tabular}{ccc}
\multicolumn{3}{c}{ SAMPLES OF GROUP 1 } \\
\hline Day & $\begin{array}{c}\text { Viable } \text { S. aureus cells } \\
\text { (CFU/ mL) }\end{array}$ & $\begin{array}{c}(\text { Log CFU/ } \\
\mathrm{mL})\end{array}$ \\
\hline 0 & $3.3 \mathrm{E}+04$ & 4.518 \\
7 & $3.4 \mathrm{E}+06$ & 6.531 \\
14 & $4.3 \mathrm{E}+08$ & 8.633 \\
21 & $3.1 \mathrm{E}+08$ & 8.491 \\
28 & $2.8 \mathrm{E}+08$ & 8.447 \\
\hline
\end{tabular}

Group 1 and group 2 eggs were used as controls. Group 1 eggs were raw eggs. Neither chitosan nor S. aureus was applied to group 1 eggs. Shell surfaces of group 1 eggs were washed with $70 \%$ ethanol. According to the results on the tables 3 and 4 , there were about $4.5 \log \mathrm{CFU} / \mathrm{mL}$ of $S$. aureus viable cells inside the eggs initially. These $S$. aureus cells might have been transferred into the eggs via the pores of eggshells before they were washed with $70 \%$ ethanol. Since all the eggs were taken from the same place, this observation suggests that there would be $S$. aureus viable cells initially inside other groups of eggs as well. Therefore, the counts of group 1 eggs provide information on cell growth by internal $S$. aureus cells, which were already invaded into the eggs prior to the experiment.

Group 3 contains chitosan-coated eggs. Group 2 contains chitosan noncoated eggs. Both groups of eggs were externally infected from $S$. aureus $\sim 10^{5} \mathrm{CFU} / \mathrm{mL}$ initial amount of cells. Growth of $S$. aureus in eggs were monitored with time. All the eggs were incubated for 28 days. Growth of S. aureus were plotted with time (Fig. 3) in order to observe variation of $S$. aureus growths in raw, chitosan-coated and chitosan-noncoated eggs.

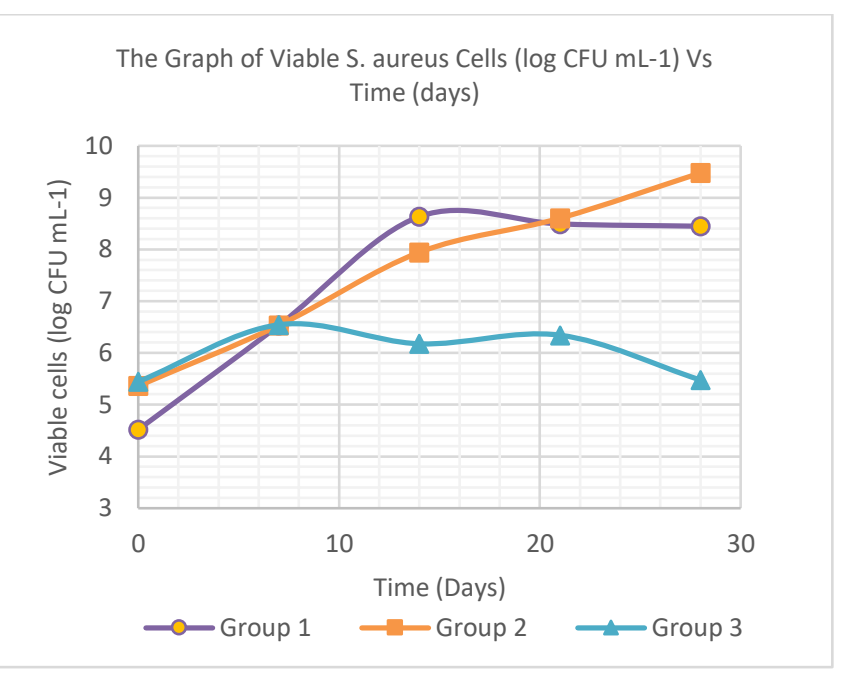

Fig. 3. Growth of $S$. aureus in group 1 (raw, but outside of the shell sterilized by $70 \%$ ethanol), group 2 (chitosan-noncoated but contaminated from Staphylococcus aureus) and group 3 (chitosan-coated and contaminated from Staphylococcus aureus) eggs.

According to the growth curves in the Fig. 3, raw eggs (group 1 eggs) has shown a typical growth curve of a bacterial population in a medium with pre-desired nutrient content. It is a typical growth curve of a batch culture. There is an exact amount of nutrients inside the egg. The graph suggests that the preinfected $S$. aureus population inside the egg was in exponential phase at the time of starting the enumeration process. After 15 days, the growth has been reached to a stationary phase. Preinfected $S$. aureus growth inside the eggs was reached maximum $8.5 \log \mathrm{CFU} / \mathrm{mL}$ within 15 days and constantly maintained until $28^{\text {th }}$ day.

The graph shows that $S$. aureus in group 2 eggs were increased gradually with time. The present study does not provide information about $S$. aureus cell counts on the surface of shells and internal contents separately. Cell counts provides information on $S$. aureus counts in whole eggs. The initial cell count in day 0 was higher than the cell count of group 1 eggs because $5 \log \mathrm{CFU} / \mathrm{mL}$ of $S$. aureus inoculum was infected to group 2 eggs externally, in addition to its internal $S$. aureus population. Growth of $S$. aureus was gradually increased up to $9.5 \log \mathrm{CFU} / \mathrm{mL}$ in 28 days. It is very high amount of $S$. aureus population. Growth curve shows that the population was still spending its exponential phase even at $28^{\text {th }}$ day. This high growth might be obtained due to migration of externally infected $S$. aureus population into the egg and colonization in internal contents and on the surface of eggshells.

According to the Fig.3, growth of $S$. aureus in whole eggs were maintained between 5.5 and $7.5 \log \mathrm{CFU} / \mathrm{mL}$ within the incubation period. The initial cell count in day 0 was higher than the cell count of group 1 eggs because $5 \log$ $\mathrm{CFU} / \mathrm{mL}$ of $S$. aureus inoculum was infected to group 3 eggs externally after chitosan was applied. The initial viable $S$. aureus count in group 3 eggs were nearly equal to that of group 2 eggs (in day 0), because both groups of eggs were externally contaminated with the same $S$. aureus inoculum and they might had nearly same amounts of pre-infected $S$. aureus cells inside the eggs at the time of infecting the external $S$. aureus inoculum. Even there were small fluctuations of growth of $S$. aureus in chitosan coated eggs, growths were maintained constantly with lower values than 
the growths of chitosan non-coated and raw eggs. In $28^{\text {th }}$ day, $S$. aureus cell count in chitosan-coated whole eggs were $5.5 \log \mathrm{CFU} / \mathrm{mL}$. It was a $4 \log \mathrm{CFU} / \mathrm{mL}$ fold growth reduction compared to $S$. aureus growth in chitosan noncoated eggs and a $3 \log \mathrm{CFU} / \mathrm{mL}$ fold growth reduction when compared to $S$. aureus growth in raw eggs.

Results in Fig. 3 has confirmed that there is an antibacterial effect of chitosan coated chicken eggs against Staphylococcus aureus. Growth curve of chitosan coated eggs suggests that the antibacterial activity is a bacteriostatic one rather than a bactericidal one. Previous studies which based on in-vitro antibacterial activity of chitosan has reported a complete inhibition of $S$. aureus by the same concentration used in this study (1.5\%). Reference [20] also observed an inhibition of Staphylococcus aureus within 2 days, under in-vitro conditions by $1.5 \%$ chitosan solution with pH 5 [20].

During the study, important visual observations on colour changes of egg yolk in each group of eggs could be made when the eggs were blending. Yellow colour of yolks of group 2 eggs were changed in to dark colour rapidly. Colour of yolks of group 2 eggs were changed in to black colour within 28 days. Yolk colour of group 1 eggs were changed in to dark yellow to brown colour within 28 days. But colour of egg yolk in group 3 eggs were remained in yellow colour and did not change significantly compared to other eggs. These colour changes might be due to toxin production, nutrient degradation and due to the end products of biochemical pathways when the organism was grown in the egg yolk. These colour changes were not included as results because no proper colorimetric investigation was done in this study.

The present study has found that use of Chitosan against staphylococcus aureus is an ideal way of preventing the contamination of raw eggs from S. aureus. Antibacterial activity of chitosan coated chicken eggs which was tested in this study can be successfully used for commercial level farm eggs with greater efficiency because, commercialized farm eggs generally have lower microbial contamination than domestic eggs. Therefore, they are initially contaminated by low amount of $S$. aureus cells due to good hygiene and proper sanitation in poultry farms. If chitosan was coated for freshly laid eggs when soon after the eggs were laid, more efficient antibacterial activity might be expected. Since chitosan forms an edible coat on the surface of eggshell, it can inhibit $S$. aureus cells which contaminates the egg. Therefore, such kind of Chitosan coated eggs will be safe to consume. On the other hand, it can reduce microbial spoilage of eggs and help to extend the shelf life of eggs. Since the previous studies [16], [29], [30] have confirmed that the chitosan coating can effectively preserve the internal quality of eggs, findings of this study on antibacterial activity of chitosan coated eggs can be used to introduce a novel product. This can be used commercially as a novel method of preserving eggs. It will also inhibit $S$. aureus transferred during handling, storage and during the selling of eggs.

\section{CONCLUSION}

The main objective of the present study was to investigate the antimicrobial effect of chitosan against $S$. aureus. The study was carried out in four steps in order to apply this antibacterial activity for safety and preservation of microbial quality of eggs.

An effective in-vitro antibacterial activity was performed by chitosan on Staphylococcus aureus. Antibacterial activity was increased with increasing concentration of chitosan. Therefore, antibacterial activity of chitosan was directly proportional to the concentration of chitosan solution used.

Staphylococcus aureus was detected with high counts in the tested egg samples. All the egg samples exceeded the maximum limit of $S$. aureus count, which has to be present in the commercially accepted poultry based raw products according to the standard guidelines. It can be concluded that these egg samples were not suitable for oral consumption.

Chitosan coated chicken eggs were able to reduce the growth of Staphylococcus aureus effectively by performing a bacteriostatic activity. Therefore, antibacterial effect of chitosan can be used to eliminate Staphylococcus aureus contamination of village chicken eggs by coating $1.50 \%$ chitosan on the outer surface of raw eggs as soon as eggs are laid.

\section{ACKNOWLEDGMENT}

The authors thank students, academic staff and nonacademic staff at the Department of Microbiology, University of Kelaniya for their support received for collecting, transporting and processing the samples used in this study.

\section{REFERENCES}

[1] I. N. Abdullah, "Isolation and identification of some bacterial isolates from table egg,” Al-Anbar J. Vet. Sci., vol. 3, no. 2, pp. 59-67, 2010.

[2] S. E. Aiello and M. A. Moses, "The Merck Veterinary Manual Online, 2011," There is no Corresp. Rec. this Ref. Sch., 2013.

[3] S. Chaemsanit, A. Akbar, and A. K. Anal, "Isolation of total aerobic and pathogenic bacteria from table eggs and its contents," Food Appl. Biosci. J., vol. 3, no. 1, pp. 1-9, 2015.

[4] Y. Le Loir, F. Baron, and M. Gautier, "Staphylococcus aureus and food poisoning," Genet Mol Res, vol. 2, no. 1, pp. 63-76, 2003.

[5] D. Stepien-Pysniak, A. Marek, and J. Rzedzicki, "Occurrence of bacteria of the genus Staphylococcus in table eggs descended from different sources," Pol. J. Vet. Sci., vol. 12, no. 4, p. 481, 2009.

[6] M. C. C. Guimarães, L. G. Amaral, L. B. A. Rangel, I. V. Silva, C. G. F. Matta, and M. F. R. de Matta, "Growth inhibition of Staphylococcus aureus by chicken egg yolk antibodies," Arch. Immunol. Ther. Exp. (Warsz)., vol. 57, no. 5, pp. 377-382, 2009.

[7] A. Menconi et al., "Effect of chitosan on Salmonella typhimurium in broiler chickens," Foodborne Pathog. Dis., vol. 11, no. 2, pp. 165 169, 2014, doi: 10.1089/fpd.2013.1628.

[8] R. N. Tharanathan and F. S. Kittur, "Chitin-the undisputed biomolecule of great potential," 2003.

[9] V. C. Wan, M. S. Kim, and S. Lee, "Water vapor permeability and mechanical properties of soy protein isolate edible films composed of different plasticizer combinations," J. Food Sci., vol. 70, no. 6, pp. e387-e391, 2005.

[10] K. Nadarajah, W. Prinyawiwatkul, H. K. No, S. Sathivel, and Z. Xu, "Sorption behavior of crawfish chitosan films as affected by chitosan extraction processes and solvent types," J. Food Sci., vol. 71, no. 2, pp. E33-E39, 2006.

[11] H. K. No, S. P. Meyers, W. Prinyawiwatkul, and Z. Xu, "Applications of chitosan for improvement of quality and shelf life of foods: A review," J. Food Sci., vol. 72, no. 5, 2007, doi: 10.1111/j.1750- 
3841.2007.00383.x.

[12] C. Jo, D. U. Ahn, X. D. Liu, K. H. Kim, and K. C. Nam, "Effects of chitosan coating and storage with dry ice on the freshness and quality of eggs," Poult. Sci., vol. 90, no. 2, pp. 467-472, 2011, doi: 10.3382/ps.2010-00966.

[13] L. Xie et al., "Edible Film Coating to Minimize Eggshell Breakage and Reduce Post-Wash Bacterial Contamination Measured by Dye Penetration in Eggs," J. Food Sci., vol. 67, no. 1, pp. 280-284, 2002.

[14] P. V Suresh, K. R. Raj, T. Nidheesh, G. K. Pal, and P. Z. Sakhare, "Application of chitosan for improvement of quality and shelf life of table eggs under tropical room conditions," J. Food Sci. Technol., vol 52, no. 10, pp. 6345-6354, 2015.

[15] H. K. No, W. Prinyawiwatkul, and S. P. Meyers, "Comparison of shelf life of eggs coated with chitosans prepared under various deproteinization and demineralization times," J. Food Sci., vol. 70, no. 6, pp. s377-s382, 2005.

[16] S. Bhale, H. K. No, W. Prinyawiwatkul, A. J. Farr, K. Nadarajah, and S. P. Meyers, "Chitosan coating improves shelf life of eggs," J. Food Sci., vol. 68, no. 7, pp. 2378-2383, 2003, doi: 10.1111/j.13652621.2003.tb05776.x.

[17] X. De Liu, A. Jang, D. H. Kim, B. D. Lee, M. Lee, and C. Jo, "Effect of combination of chitosan coating and irradiation on physicochemical and functional properties of chicken egg during room-temperature storage," Radiat. Phys. Chem., vol. 78, no. 7-8, pp. 589-591, 2009.

[18] M. Ye, H. Neetoo, and H. Chen, "Effectiveness of chitosan-coated plastic films incorporating antimicrobials in inhibition of Listeria monocytogenes on cold-smoked salmon," Int. J. Food Microbiol., vol. 127, no. 3, pp. 235-240, 2008.

[19] S. Leleu et al., "Effects on Salmonella shell contamination and transshell penetration of coating hens' eggs with chitosan," Int. J. Food Microbiol., vol. 145, no. 1, pp. 43-48, 2011.

[20] G. H. Wang, "Inhibition and inactivation of five species of foodborne pathogens by chitosan," J. milk food Technol., vol. 55, no. 11, pp. 916-919, 1992.

[21] ISO-6888, "Horizontal method for the enumeration of coagulasepositive staphylococci (Staphylococcus aureus and other species)," vol. 1999, pp. 10-12, 1999.

[22] P. Fernandez-Saiz, C. Soler, J. M. Lagaron, and M. J. Ocio, "Effects of chitosan films on the growth of Listeria monocytogenes, Staphylococcus aureus and Salmonella spp. in laboratory media and in fish soup," Int. J. Food Microbiol., vol. 137, no. 2-3, pp. 287-294, 2010, doi: 10.1016/j.ijfoodmicro.2009.11.016.

[23] Food Standards Australia New Zealand, "Staphylococcus aureus," 2013.

[24] D. Raafat and H.-G. Sahl, "Chitosan and its antimicrobial potential - a critical literature survey," Microb. Biotechnol., vol. 2, no. 2, pp. 186201, Mar. 2009, doi: 10.1111/j.1751-7915.2008.00080.x.

[25] G. Tsai and W. Su, "Antibacterial activity of shrimp chitosan against Escherichia coli," J. Food Prot., 1999.

[26] A. K. Singla and M. Chawla, "Chitosan: Some pharmaceutical and biological aspects-an update," J. Pharm. Pharmacol., vol. 53, no. 8, pp. 1047-1067, 2001.

[27] C. Chen, W. Liau, and G. Tsai, "Antibacterial effects of N-sulfonated and N-sulfobenzoyl chitosan and application to oyster preservation," J. Food Prot., 1998.

[28] S. Lanka, V. Place, and E. Mawatha, "Schedule of Accreditation," Int. Lab., vol. 150, no. December 2007, pp. 1-19, 2010.

[29] C. Caner, "The effect of edible eggshell coatings on egg quality and consumer perception," J. Sci. Food Agric., vol. 85, no. 11, pp. 18971902, 2005, doi: 10.1002/jsfa.2185.

[30] S. H. Lee, H. K. No, and Y. H. Jeong, "Effect of chitosan coating on quality of egg during storage," J. Korean Soc. Food Nutr. (Korea Republic), 1996.

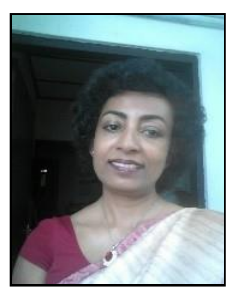

G. D. Deepthi K. Gunasena was born in Sri Lanka in 1967. Deepthi obtained B. Sc. Honors Degree in microbiology from University of Kelaniya, Sri Lanka in 1994 and $\mathrm{PhD}$ in microbiological food safety from University of Reading, United Kingdom in 2005.

Currently, she is working as a Senior Lecturer (Grade I) and Head of the Department at Department of Microbiology, University of Kelaniya, Sri Lanka. Her major publications include:

1. Gunasena, D.K., Komrower, J. and MacIntyre, S. (2003), The fish pathogen Yersinia ruckeri possesses a Type III secretion system. 105107pp. In Skurnik, M., Bengoechea, J. A., Granfors, K. (Eds.), Advances in Experimental Medicine and Biology, Vol. 529, Springer Publishers, ISBN
978-0-306-477591.

2. Deepthi K Gunasena and Dilumi B Wickramaratne Molecular diversity among autochthonous Lactobacillus strains in spontaneously fermented traditional Sri Lankan Mudawapu kiri from Kanthale, Sri Lanka, (2017) 6th International Conference and Exhibition on Probiotics, Functional and Baby Food. Journal of Probiotics Health, London, UK Vol: 5 (3) p. 44, ISSN: 2329-8901.

Her research interests are microbiological food safety- characterization of pathogenic bacteria in food, beneficial bacteria in food- study on Lactobacillus species in traditional foods in Sri Lanka, and biopreservation of food - effect of natural microbiota and natural antimicrobials.

Ms. Gunasena is a life member of Institute of Biology in Sri Lanka, Sri Lanka Association for the Advancement of Science, and Sri Lanka Association for the Fisheries and Aquatic Resources. Ms. Gunasena was also a member of the Society for General Microbiology in United Kingdom from 2000 to 2004 .

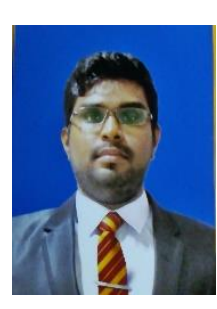

B. G. Eranga T. Jayashantha was born in Sri Lanka in 1991. Eranga obtained B. Sc. Honors Degree in microbiology from University of Kelaniya, Sri Lanka in 2017 and Diploma in Quality Management from Sri Lanka Standards Institution in 2019. Eranga has also completed assessor training certificate for Laboratory Quality Management Systems as per ISO 17025 at Sri Lanka Accreditation Board.

Currently, he is working as the Group Quality Control Specialist at ORANA A/S for 1.5 years and previously was working as the Microbiologist in Prima, Sri Lanka for 2 years.

Mr. Jayashantha is an associate member of Institute of Food Science and Technology (IFST-UK). He holds full membership of Society of Quality Assurance (SQA-USA). He is a full member of International Fruit and Vegetable juice Association (IFU) and its food microbiology working group. Furthermore, he is a member of Global Harmonization Initiative (GHI) and its working committee in Microbiology. Mr. Jayashantha was awarded the gold medal for the best research presentation in food science and technology at AGRICO 2018.

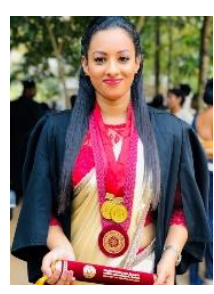

D. G. Nimesha S. Senevirathne was born in Sri Lanka in 1994. Nimesha obtained B. Sc. Honors Degree in microbiology from University of Kelaniya, Sri Lanka in 2019.

Currently, she is working a temporary demonstrator at Department of Microbiology, University of Kelaniya, Sri Lanka. She has presented her research at several scientific conferences. She is interested in food microbiology and environmental microbiology research.

Ms. Senevirathne was awarded the gold medal presented by the Alumni Association of the Faculty of Science, University of Kelaniya, Sri Lanka for the best performance in microbiology at the B. Sc. Honors Degree Examination of January/ February 2019. 